\title{
Can pediatricians learn from other cultures and social contexts in the U.S.?
}

\author{
Robert A. LeVine* \\ Professor of Education and Human Development, Emeritus, Harvard University, USA
}

In our book Do Parents Matter? (2016, PublicAffairs), Sarah LeVine and I offer - as an example of how we can learn from other cultures the case of mother-infant co-sleeping, a standard practice in most of the non-Western world, including the communities in which we have worked as anthropologists in Africa, Latin America and South Asia. Our suggestion in the book (and in a September 18th opinion piece in the Los Angeles Times) that American parents might consider adopting this practice has proved controversial and drawn severe criticism from pediatricians and pathologists, including the president of the American Academy of Pediatrics, Bernard Dreyer, MD (in a letter to the Los Angeles Times, September 22, 2016).

Dr. Dreyer and the others cite evidence that significant numbers of American babies die sleeping in bed with their mothers. But they seem unwilling to consider powerful evidence that raises questions about their attribution of those deaths to bed-sharing per se. One type of evidence is cross-cultural: In Japan, a large, rich country, children generally sleep with their mothers from birth until at least ten years of age, and Japan's infant mortality rate is 2.8 (per thousand live births) as compared with 6.2 the United States, and Japan's rate of SIDS (Sudden Infant Death Syndrome) is roughly half the U.S. rate [1].

Why hasn't the AAP sent a delegation to Japan to find out how they do it? One of our pediatric critics mentions that the Japanese sleep on a futon or firm mat, but he doesn't argue that this practice could be emulated or even considered as an alternative by American parents. He seems to rule out learning from other peoples' practices, whereas we argue that it is exactly what a Darwinian science of human parenting should be doing.

Copyright: (C2016 LeVine RA. This is an open-access article distributed under the terms of the Creative Commons Attribution License, which permits unrestricted use, distribution, and reproduction in any medium, provided the original author and source are credited.
Another problem with the AAP position is that it doesn't take into account some primary contexts of American parenting, especially social class. In the U.S. there is poverty, and impoverished mothers are less likely to get or seek pediatric guidance, are more likely to be obese and to engage in unhealthy practices like smoking in bed, all of which may be risk factors for infant death when bed-sharing. But unless the Academy is willing to examine the social contexts across which these risk factors are distributed, and to delve into how parents think and feel about them, their protests that babies die from bed-sharing remains problematic. That pediatricians don't consider themselves qualified to conduct a social and cultural analysis is understandable, but then why doesn't the Academy consult sociologists and anthropologists to gain a deeper understanding of the conditions of infant deaths?

That brings us to Professor James McKenna of the University of Notre Dame, a biological anthropologist whose laboratory experiments of mothers with their babies in our society are unique in providing evidence for the value of "breast-sleeping" [2]. He makes a convincing case for an American return to what were universal human norms of infant care until the second half of the $19^{\text {th }}$ century.

\section{References}

1. LeVine RA, LeVine S (2016) Do Parents Matter? New York: Public Affairs.

2. McKenna JJ, Gettler LT (2016) There Is No Such Thing as Infant Sleep. There Is No Such Thing as Breast-Feeding. There Is Only Breastsleeping. Acta Paediatr 105: 1721. [Crossref]
Correspondence to: Robert A. LeVine, Professor of Education and Human Development, Emeritus, Harvard University, USA, Tel: (617) 484-4739, E-mail: levine68@gmail.com

Received: December 04, 2016; Accepted: December 21, 2016; Published: December 23, 2016 